\title{
L-SHaped Slot LoAded SEMicircular Patch ANTENNA FOR WIDEBAND OPERATION
}

\author{
AMEL BOUFRIOUA \\ Electronics Department, Technological Sciences Faculty, University Constantine 1, \\ Constantine, Algeria
}

\begin{abstract}
In this paper, a dual frequency resonance antenna is analysed by introducing L-shaped slot in a semi circular patch, different parametric studies have allows and the results in terms of return loss and radiation pattern are given. The results show that dual wide bands are achieved and a better impedance matching for the upper and lower resonance are obtained. Also, it is observed that various antenna parameters are obtained as a function of frequency for different value of slot length and width; it is easy to adjust the upper and the lower band by varying these different antenna parameters. The coaxial feed is used to excite the patch antenna. Theoretical results using Matlab are compared with the simulated results obtained from Ansoft HFSS software and shown to be in good agreement.
\end{abstract}

\section{KEYWORDS}

L-shaped, slot loaded, semicircular patch antenna, wideband operation.

\section{INTRODUCTION}

Today, the state of the art antenna technology allows the use of different types and models of antennas, depending on the area of application considered. With the rapid development of wireless communications, it is desirable to design small size, low profile and wideband multifrequency planar antennas. Microstrip antennas are now extensively used in various communication systems due to their compactness, economical efficiency, light weight, low profile and conformability to any structure. The main drawback to implementing these antennas in many applications is their limited bandwidth. However, the most important challenge in microstrip antenna design is to increase the bandwidth and gain [1-14]. Several techniques that can be used to achieve multi-band performances such as multilayer stacked patch, multi resonator and insertion of slots and slits [2] of various shapes and sizes in the patch antennas have been proposed recently [1-14]. When a microstrip patch antenna is loaded with reactive elements such as slots, stubs or shorting pin, it gives tunable or dual frequency antenna characteristics [6]. The most popular technique for obtaining dual-frequency behaviour is to introduce the slots on a single patch [1-4]. Since the slots are cut at an appropriate position inside the patch, they neither increase the patch size nor largely affect the radiation pattern of the patch [11]. These slots can take different shapes like, rectangular or square slot, step slot, tooth-brush shaped slot, V-slot, Uslot, etc [11]. The slot adds another resonant mode near the fundamental mode of the patch and realizes dual frequency response [11].

In this paper, we present a semicircular microstrip patch antenna with L-shaped slot. The proposed antenna can completely cover two bands and provides a significant size reduction. Dual

DOI : 10.5121/ijwmn.2014.6608 
frequency is tuned by changing the dimensions of the slot. In this paper the simulation resultants and the performance analyses using high frequency structure simulator (HFSS) software and Matlab of the proposed semicircular microstrip patch antenna with L-shaped slot are presented, different parametric studies will be allowed and the effect of the various antenna parameters on the return loss and the radiation of the proposed antenna will be presented, also we will present the effect of the substrate on the band width and the return loss with lower and upper resonant frequencies.

\section{ANTENNA CONFIGURATION}

The configuration of the proposed antenna is shown in Fig. 1. The semi circular microstrip patch of dimensions $\mathrm{W} \times \mathrm{L}$ printed on the grounded substrate, which has a uniform thickness of $h$ and having a relative permittivity $\varepsilon_{\mathrm{r}}$ and the dielectric material is assumed to be nonmagnetic with permeability $\mu_{0}$. The analysis of the half disk patch antenna is similar to that of circular disk patch, but the effective radius changes to $50 \%$ reduction in size [6]. The L-shaped slot with dimension (Ls, Ws) is embedded in a semicircular patch (see Figure 2); the L-shaped patch semicircular antenna features dual-band behaviour.

The patch is fed by a probe coaxial $(50 \Omega)$ which is easy to fabricate and has spurious radiation [14]. In this feeding technique, the inner conductor of the coaxial connector extends from ground through the substrate and is soldered to the radiating patch, while the outer conductor extends from ground up to substrate.

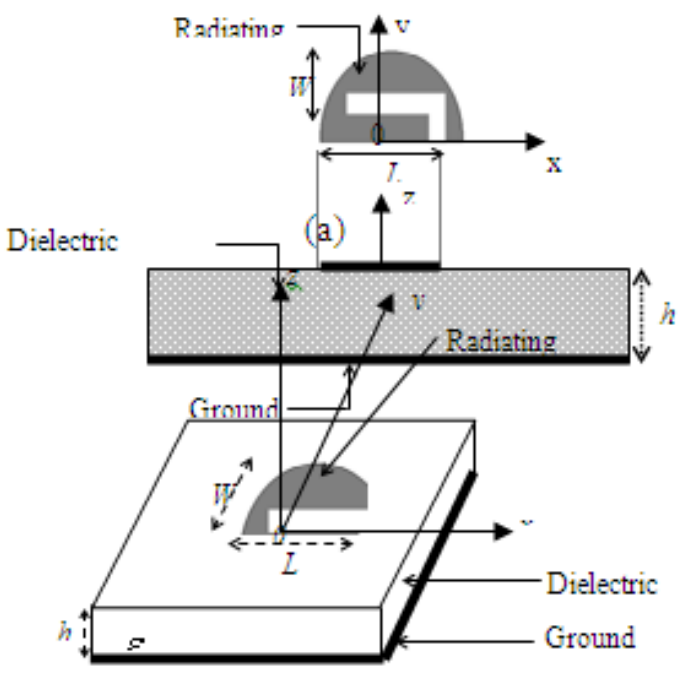

Figure 1. Geometry of L-shaped slot loaded semicircular disk patch antenna; (a) side view, (b) top view 


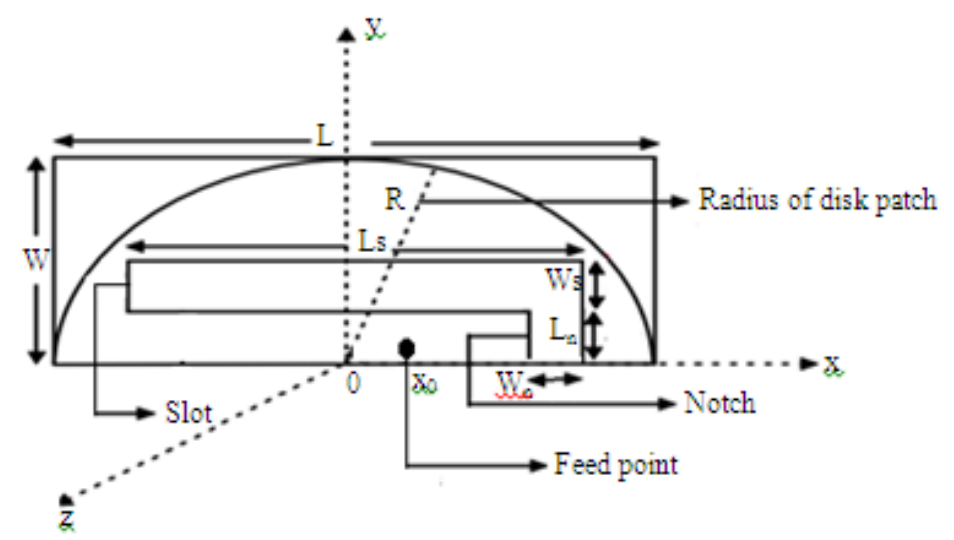

Figure 2. Dimensions of L-shaped slot loaded semicircular disk patch antenna

\section{NUMERICAL RESULTS AND DISCUSSION}

Table 1 shows the different parameters of this proposed semicircular patch antenna loaded with an L-shaped slot with $\square \mathrm{r}=1$. It is worth noting that the feed can be placed at any desired location inside the patch. In this study the feeding is accomplished with a probe coaxial located on the axial of symmetry of the antenna in the point of coordinates $\mathrm{x}_{0}$ and $\mathrm{y}_{0}$.

The simulation is done through programs in Matlab and Ansoft HFSS, which is based on Finite Element Method; we compare our results with those available in the reference [6].

Table1. Design parameters of the proposed antenna.

\begin{tabular}{|l|l|l|l|l|l|l|l|}
\hline Parameters & $\mathrm{R}$ & $\mathrm{h}$ & $\mathrm{Ls}$ & $\mathrm{Ws}$ & $\mathrm{Wn}$ & $\mathrm{Ln}$ & $\left(\mathrm{x}_{0}, \mathrm{y}_{0}\right)$ \\
\hline Value (mm) & 40 & 15 & 46.2 & 6 & 2.5 & 6 & $(12.6,0)$ \\
\hline
\end{tabular}

The return loss is studied in function of frequency; the effect of different physical parameters on the characteristics of the patch antenna is shown. From (figures 3a and b) given by Malab code and HFSS software respectively it is clear that the proposed antenna resonate at two frequencies with two band widths

That is seen from the (Figure3. A), given by Matlab2013 code that the lower resonant frequency fr $1=1.48 \mathrm{GHz}$ and the upper resonant frequency fr $2=2.28 \mathrm{GHz}$. The $-10 \mathrm{~dB}$ band width of lower and upper resonance frequencies are respectively $\mathrm{BP} 1=14.86 \%, \mathrm{BP} 2=10.96 \%$

From (Figure 3. b) obtained from HFSS14.0 software the two resonant frequencies are fr $1=1.42 \mathrm{GHz}$; fr2 $=2.23 \mathrm{GHz}$. The $-10 \mathrm{~dB}$ band width of the previous lower and upper resonance frequencies are respectively $\mathrm{BP} 1=8.42 \%, \mathrm{BP} 2=19.74 \%$.

The reflection coefficients values that are achieved at theses resonant frequencies are lower than $22 \mathrm{~dB}$. These reflection coefficients values suggest that there is good matching at the frequency point below the $-10 \mathrm{~dB}$ region.

The theoretical results using Matlab are found to be approximately in good agreement with the simulated results obtained with Ansoft HFSS software and with [6]. 
International Journal of Wireless \& Mobile Networks (IJWMN) Vol. 6, No. 6, December 2014

In the following Figures (4-14), the theoretical results are obtained from Matlab code.

Figures 4 and 5 show respectively the effect of the relative permittivity and the substrate thickness on the return loss and frequency of the proposed L-shaped slot loaded semicircular disk patch antenna. It can be see clearly that the substrate has a stronger effect on both the lower and upper resonant frequencies.

The effect of the radius $\mathrm{R}$ of the disk patch on the return loss and frequency is given in Figure 6.

The variation of return loss S11 according to slot length "Ls" is shown by Figure 7, it is observed that the increase of the Ls, increases both the lower and the upper resonance frequencies.

For the variation of S11 according to slot width Ws shown by Figure 8, it is observed that the upper gap of the resonance frequencies increase with increasing value of the slot width. It can be seen clearly that the slot length Ls and slot width Ws have a stronger effect on the lower resonance frequencies than the upper resonant frequencies.

Figures 9 and 10 show the variation of the return loss with frequency for different value of notch length and width respectively, it is observed that the notch length Ln and notch width Wn have a stronger effect on the upper resonance frequencies which increase with the increasing value of the notch length and decrease with the increasing value of the width length than the lower ones which almost remain constant for the variation of these parameters ( $\mathrm{Ln}$ and $\mathrm{Wn}$ ).

From Figure 11, it can be observed that when the notch length equal to the slot width, the variation of this two parameters together have a stronger effect on both the lower and upper resonance frequency compared to previous Figures 8 and 9 which show that for the Figure 8, the variation of the slot width has slightly effects the upper resonant frequency and has a stronger effect on the lower resonant frequency, however for Figure 9, it is clear that the variation of the notch length has slightly effects the lower resonant frequency (almost remain constant) and has a stronger effect on the upper resonant frequency.

In Figure 12, it is shown that the feed locations have a stronger effect on both the lower and the upper resonance frequencies; furthermore the obtained results show that the lower resonance frequencies vary more significantly when the $\mathrm{x}_{0}$ change compared to the upper resonance frequencies as well as the other physical parameters of the proposed antenna.

Radiation pattern of the antenna is shown in Figure 13 and 14 for both upper and lower resonance in both principal planes $\mathrm{E}$ and $\mathrm{H}$. 
International Journal of Wireless \& Mobile Networks (IJWMN) Vol. 6, No. 6, December 2014

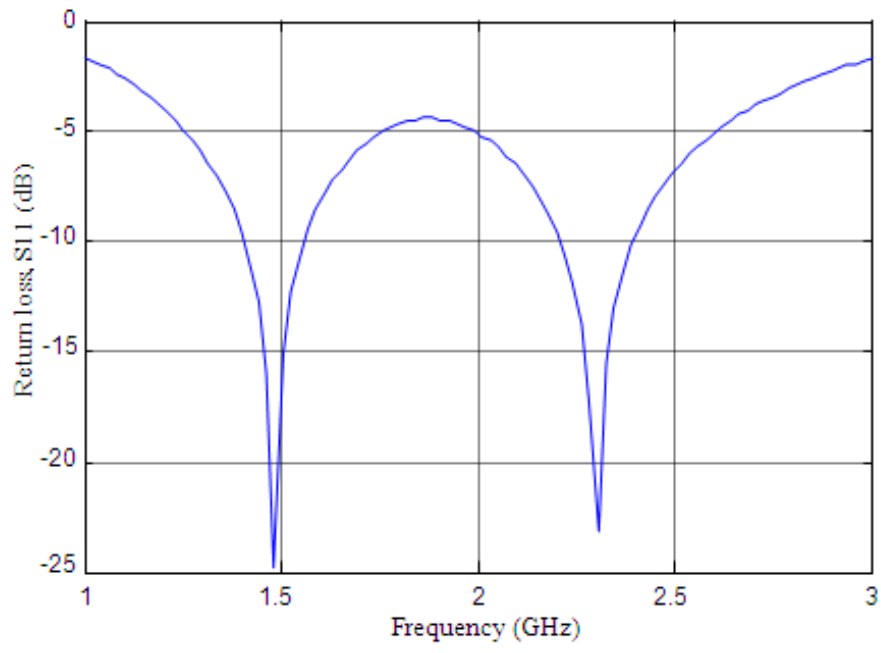

(a)

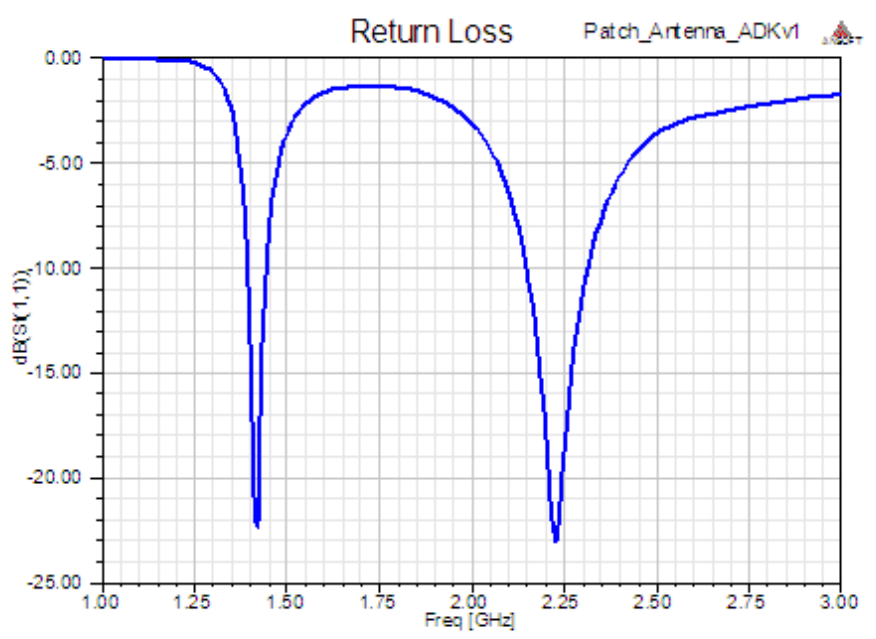

(b)

Figure 3. Comparative plot of return loss with frequency along with theoretical results obtained from Matlab code (a) and simulated results obtained from Ansoft HFSS software (b). 
International Journal of Wireless \& Mobile Networks (IJWMN) Vol. 6, No. 6, December 2014

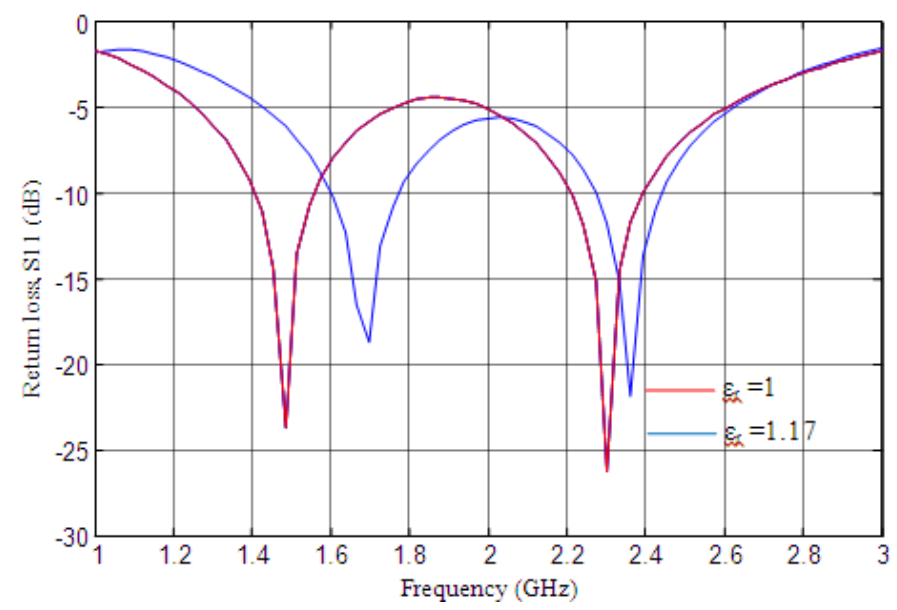

Figure 4. Effect of the relative permittivity on the return loss and frequency of the proposed L-shaped slot loaded semicircular disk patch antenna.

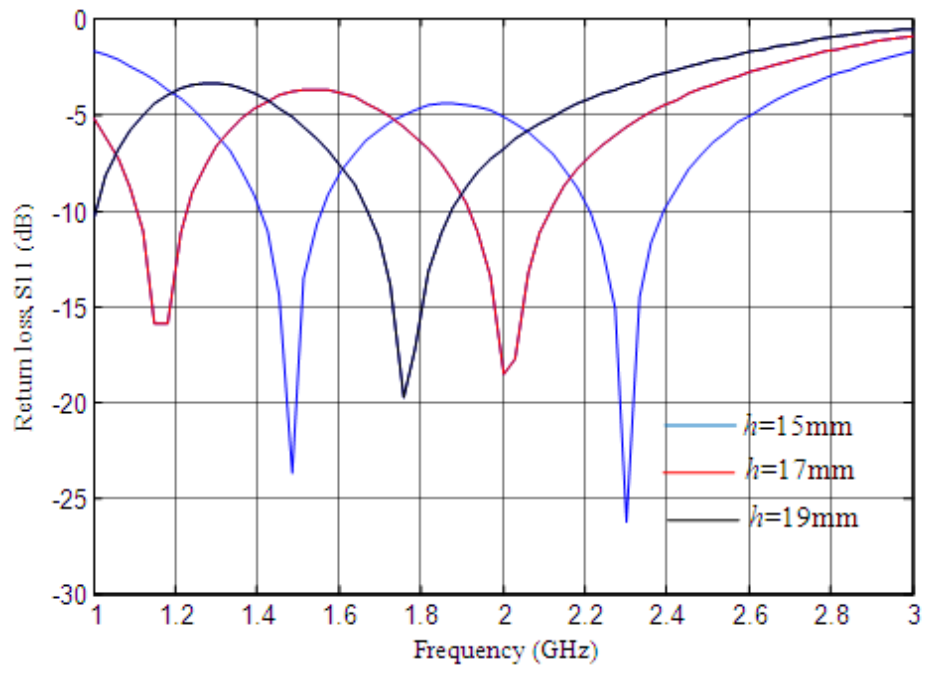

Figure 5. Effect of the substrate thickness on the return loss and frequency of the proposed L-shaped slot loaded semicircular disk patch antenna. 
International Journal of Wireless \& Mobile Networks (IJWMN) Vol. 6, No. 6, December 2014

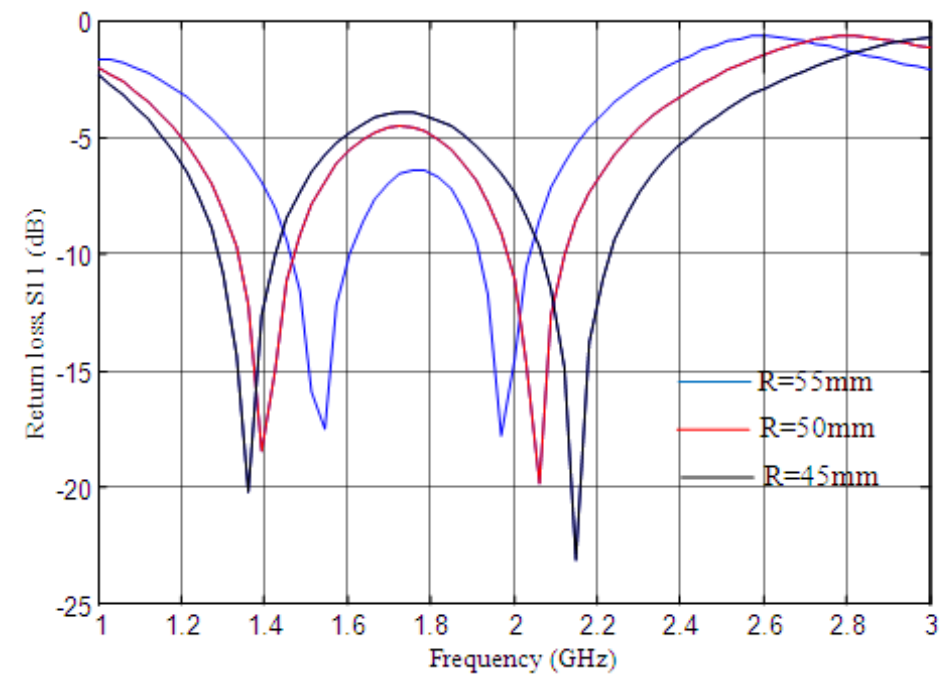

Figure 6. Effect of the radius of disk patch $\mathrm{R}$ on the return loss and frequency of the proposed L-shaped slot loaded semicircular disk patch antenna.

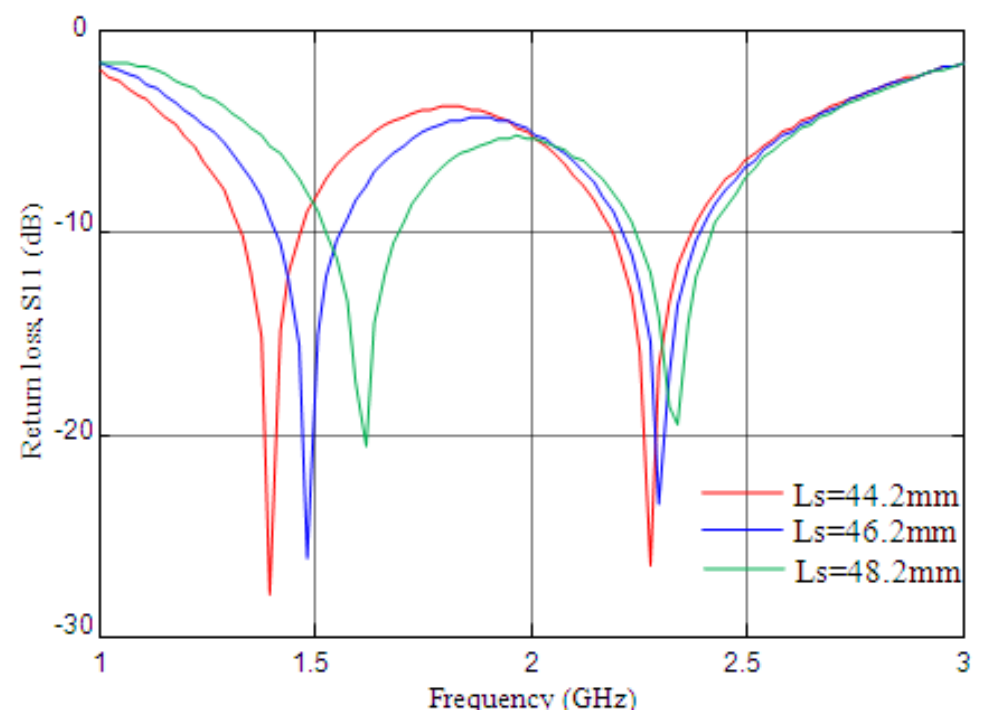

Figure 7. Variation of return loss S11 with frequency obtained from Matlab code for different value of slot length Ls. 
International Journal of Wireless \& Mobile Networks (IJWMN) Vol. 6, No. 6, December 2014

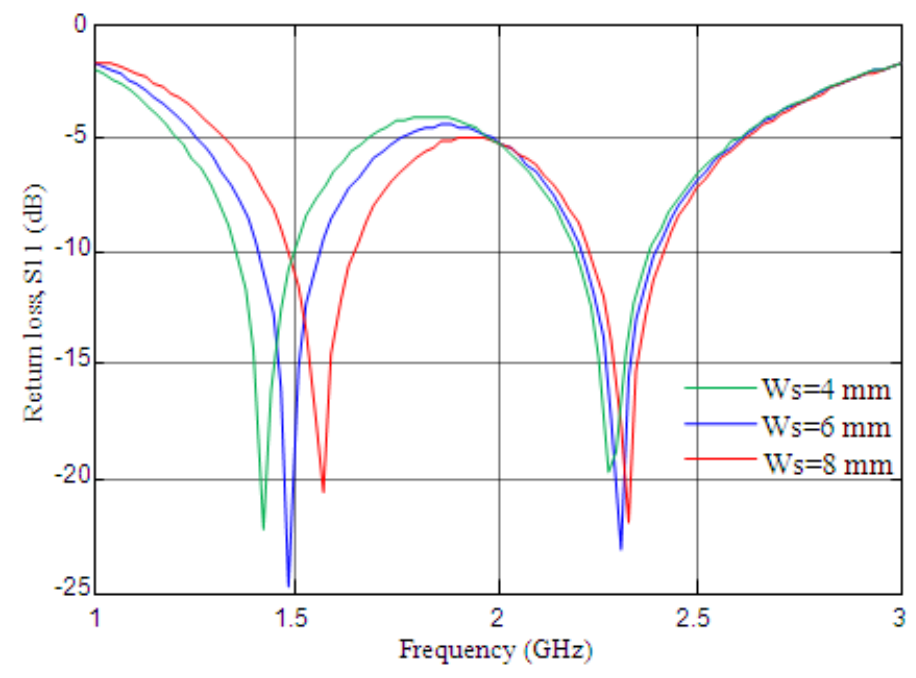

Figure 8. Variation of return loss S11 with frequency obtained from Matlab code for different value of slot width Ws.

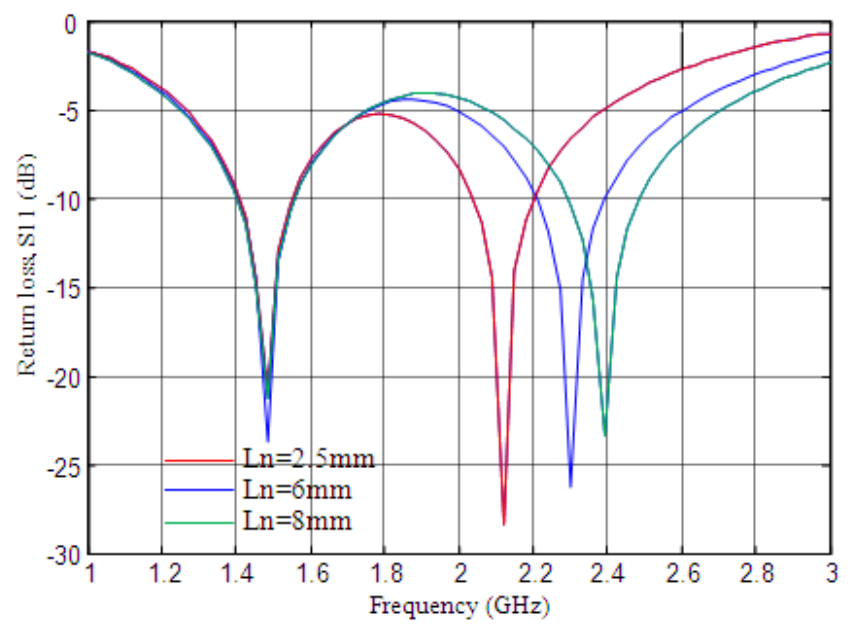

Figure 9. Variation of return loss with frequency for different value of notch length "Ln" 
International Journal of Wireless \& Mobile Networks (IJWMN) Vol. 6, No. 6, December 2014

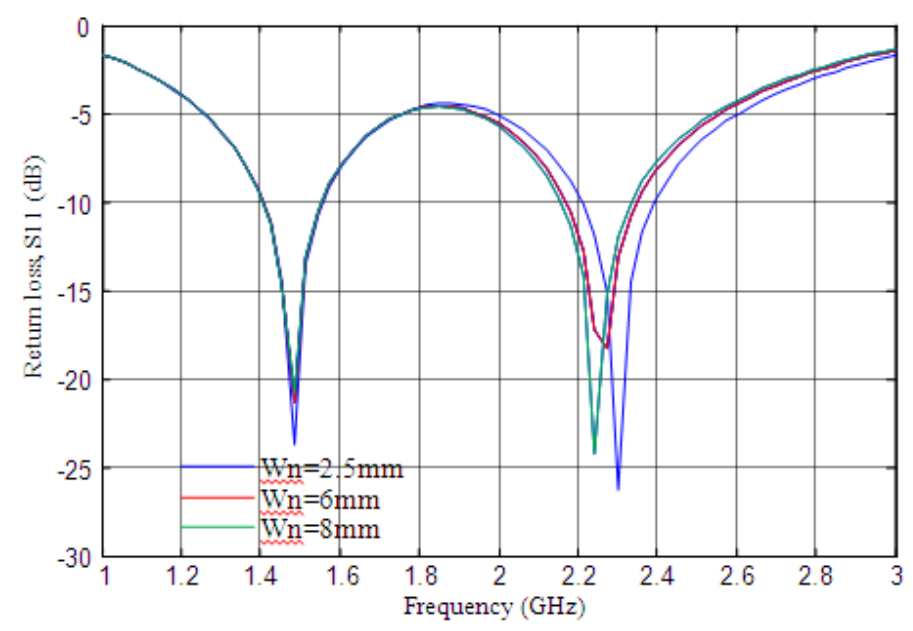

Figure 10. Variation of return loss with frequency for different value of notch width "Wn"

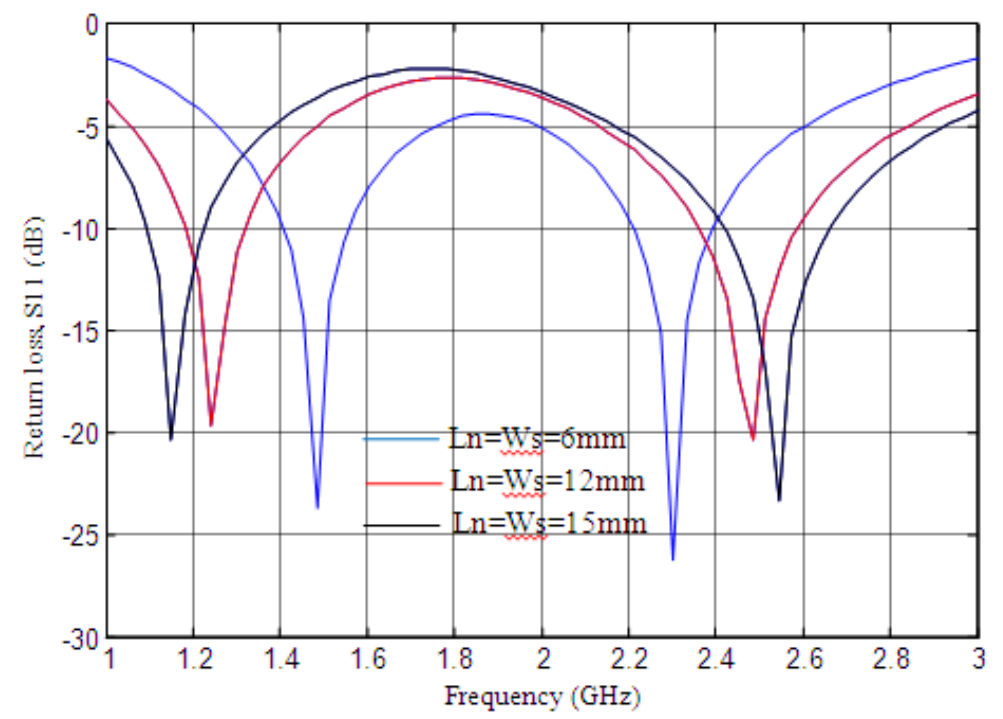

Figure 11. Variation of return loss with frequency for different value of the notch width and length with the notch length equal to the notch width 
International Journal of Wireless \& Mobile Networks (IJWMN) Vol. 6, No. 6, December 2014

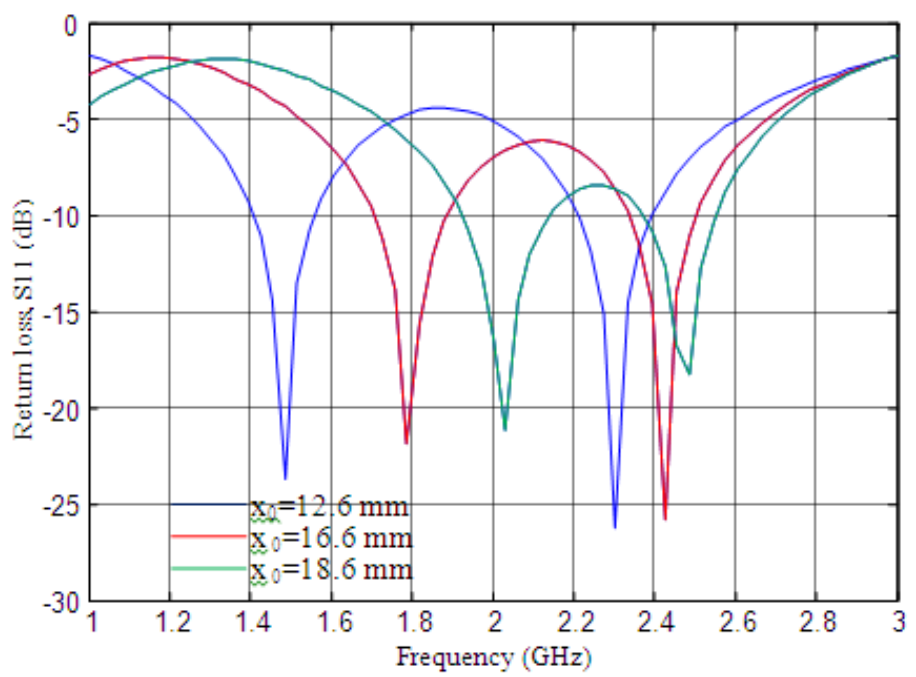

Figure 12. Variation of return loss with frequency for different value of feed point " $\mathrm{x}_{0}$ "

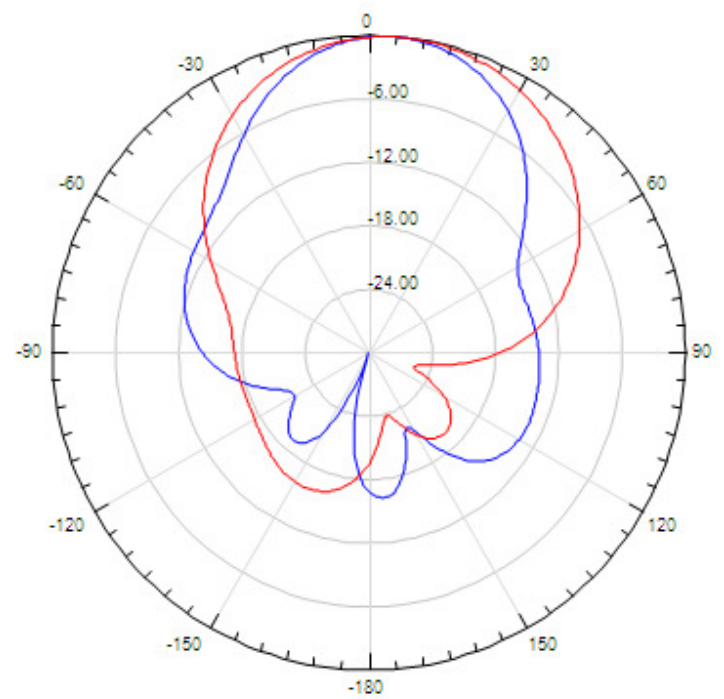

Figure 13. Radiation pattern of L-shaped slot loaded semicircular patch antenna for both upper resonant frequency (blue line) and lower resonant frequency (red line) at E plane 


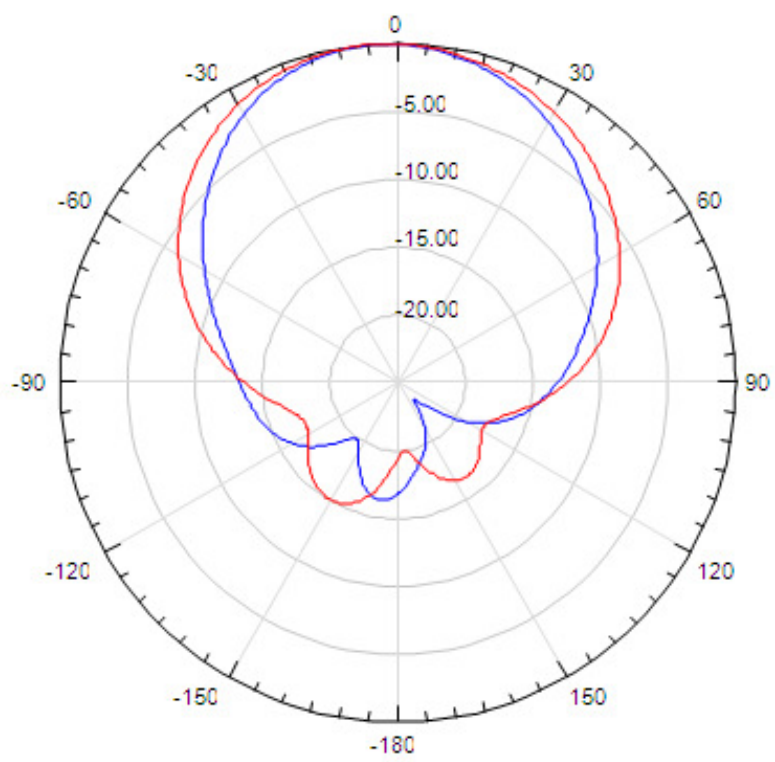

Figure 14. Radiation pattern of L-shaped slot loaded semicircular patch antenna for both upper resonant frequency (blue line) and lower resonant frequency (red line) at $\mathrm{H}$ plane

\section{CONCLUSION}

It is found that the proposed L-shaped slot loaded semicircular patch structure can operate at two resonance frequencies and consequently this proposed antenna can be used for dual band operation, also the effects of different physical parameters on the characteristics of this structure are investigated, furthermore the effect of the substrate on the band width and the return loss with lower and upper resonant frequencies is given, the proposed structure can be scaled to meet different frequencies of wireless communication systems just by changing the dimension of the main antenna. Numerical results indicate that both the upper and lower resonant frequencies and the band widths depend on the size of the slot dimensions, by properly choosing the location of feed point and the slots two bands can be achieved and controlled. Furthermore, the lower resonant frequencies and band widths are highly dependent on the slot dimensions as well as feed locations, however the upper resonant frequencies and band widths are highly dependent on the notch dimensions. In addition, the radiation pattern of both upper and lower resonant frequencies of the proposed antennas are presented in the principal planes $\mathrm{E}$ and $\mathrm{H}$.

\section{REFERENCES}

[1] J. A. Ansari, P. Singh and S. K. Dubey, (2008) "H-shaped stacked patch antenna for dual band operation,” Progress In Electromagnetics Research B, Vol. 5, pp. 291-302.

[2] A. A. Razzaqi, M. Mustaqim and B. A. Khawaja, (2013) "Wideband E-Shaped Antenna Design for WLAN Applications," (ICET), IEEE 9th International Conference on Emerging Technologies, 9-10.

[3] S. Maci and G. B. Gentili, (1997) "Dual-Frequency Patch Antennas "IEEE Antennas \& Propagation Magazine, Vol. 39, No. 6.

[4] I-F. Chen, C. M. Peng, and S-C. Liang, (2005) "Single Layer Printed Monopole Antenna for Dual ISM-Band Operation,” IEEE Trans. On Antennas and Propaga., Vol.53, N. 4. pp. 1270-1273. 
International Journal of Wireless \& Mobile Networks (IJWMN) Vol. 6, No. 6, December 2014

[5] J A. Ansari, S. K. Dubey, P. Singh, R. U. Khan, B. R.Vishvakarma, (2008) "Analysis of U-slot loaded patch for dualband operation," International Journal of Microwave and Optical Technology, Vol. 3, pp. 80-84.

[6] J. A. Ansari, A. Mishra, (2011) "Half U-slot loaded semicircular disk patch antenna for GSM mobile phone and optical communications," Progress In Electromagnetics Research C, Vol. 18, pp. 31-4.

[7] D. K. Srivastava, J. P. Saini, D. S. Chauhan, (2009) "Broadband stacked H-shaped patch antenna," International Journal of Recent Trends in Engineering, Vol. 2, pp. 385-389.

[8] E. Wang, J. Zheng, (2009) "A novel dual-band patch antenna for WLAN communication," Progress In Electromagnetics Research C, Vol. 6, pp. 93-102.

[9] A. Boufrioua, A. Benghalia, (2006) "Effects of the resistive patch and the uniaxial anisotropic substrate on the resonant frequency and the scattering radar cross section of a rectangular microstrip antenna" Elsevier, AST, Aerospace Science and Technology, Vol. 10, pp. 217-221.

[10] A. Boufrioua, (2014), "Bilayer microstrip patch antenna with loaded with U and half U-shaped slots," (ICMCS), IEEE International Conference on multimedia computing and systems, 14-16.

[11] A. A. Deshmukh, K. P. Ray, (2010), "Resonant length formulations for dual band slot cut equilateral triangular microstrip antennas," Wireless Engineering and Technology, Vol. 1, pp. 55-63.

[12] H. F. Pues and A. R. Van De Capelle, (1989), "An impedance matching technique for increasing the bandwidth of microstrip antennas,” IEEE Trans Antennas Propagat, Vol. 37, pp. 1345-1354.

[13] M. K. Meshram, B. R. Vishvakarma, (2001), "Gap-coupled microstrip array antenna for wide-band operation," International Journal of Electronics, Vol. 88, pp. 1161-1175.

[14] I. J. Bahl and P. Bhartia, (1980) Microstrip antennas, Edited by M. A Dedham, Artech House.

\section{Authors}

Amel Boufrioua was born in Constantine, Algeria; she received the B.S. degree in Electronic Engineering in 1996, the M.S. and Ph.D. degrees in Microwave from Electronics Department, Constantine University, Algeria, in 2000 and 2006 respectively. From February 2002 to December 2003, she was a Research Assistant with Space Instrumentation Laboratory at the National Centre of Space Techniques "CNTS" (Oran, Algeria), and then in November 2003, she was an Assistant Professor at the Electronic Engineering Department (Constantine University). Since 2008, she is a Lecturer with the electronic department, University Constantine 1; her area of interest is microwave and microstrip antennas. 